near $400^{\circ} \mathrm{C}$ and the differences between low-rank and coking coals are now largely understood in general terms. Radioactive labelling using tritium has been used to determine the origin of fine material produced when a range of sizes is broken in a centri- fuged mill; photoelasticity has been applied in a preliminary study of the stress distribution in particles and mill elements; and the energy required for fracture has been determinod by controlling the propagation of a crack in a coal specimen.

\title{
NUTRITION OF THE EXPECTANT AND NURSING MOTHER
}

$\mathrm{P}$ REGNANCY imposes considerable nutritional stress on the mother. The growth of the foetus, and enlargement and hypertrophy of the organs of reproduction and lactation, and the inerease in the volume of circulating blood are important physiological changes occurring during pregnancy and lactation which increase the nutritional requirements during this period. To give precise information on the physiological changes that occur in Indian women, and the magnitude of the nutritional strain to which they are exposed, in recent years the Indian Council of Medical Research has embarked on a series of investigations. Studies have been made on the body composition in terms of coll mass, extra-cellular water, fat and active formation of lean body mass during the second trimester of pregnancy*.

It has been observed that the basic metabolism is increased in nursing women to the extent of nearly 26 per cent over the average basic metabolie rate of normal adult women; this is, presumably, due to the energy required in the production of milk. These, and othor studies, are providing clear-cut knowledge about the nutritional requirements during pregnancy and lactation of Indian women. Such knowledge will lead to a more realistic planning of diets during these periods of physiological stress.

Attention was also directed to the composition and nutritive value of breast milk in Indian women. Special investigations have been undertaken by the

* Indian Council of Medical Research. Report for the years 1958-50 and $1250-60$. pp. iv +274 . (New Delhi: Indian Council of Medical Research, 1960.)
Council to determine the concentration of nutrients in breast milk of poor Indian women and to explore the possibility of improving the nutritive quality of this milk by supplementing the mother's diet, thus benefiting in one operation both the mother and the suckling infant. Studies on the chemical composition revealed that, while the concentration of proximate principles compared well with those observed in well-nourished populations, the concentration of several vitamins in the samples from poor Indian wormen was much lower. It was also observed that supplementation of the maternal diet with thiamine and ascorbic acid led to significant increase in the concentration of those vitamins in breast milk, although a similar effect was not observed with vitamin $A$ and iron.

Studies on the output of breast milk in different stages of lactation revealed that poor Indian women are in a state of almost continuous lactation throughout the child-bearing period of their lives. The implications of this observation from the point of view of health and nutritional status of the mother require careful consideration. One study, using various levels of dietary protein and measuring nitrogen balance, revealed that $0.14 \mathrm{~g}$ of nitrogen per $\mathrm{kg}$ per day would be the minimum nitrogen intake needed for maintaining equilibrium. On this basis, the minimum amount of dietary protein requirements, between 22 and 28 weeks of pregnancy, would work out to $0.9 \mathrm{~g}$ per $\mathrm{kg}$ per day, or $40.5 \mathrm{~g}$ per day for a pregnant woman of average weight of $50 \mathrm{~kg}$.

\section{SCOTTISH PALAOBOTANY}

$\mathrm{T}$ WO papers, recently published by the Royal Society of Edinburgh, add to, and at the same time simplify, knowledge of previously known plants*. K. M. Lele and J. Walton have investigated Zosterophyllum, which, after repeated investigation, is appearing as a tufted rhizomatous Pteridophyte widespread on Lower Devonian marshes. The most useful of the new material consists of axes freed when rock was dissolved in the preparations of a balsam transfer; some of these axes had rotted before preservation and consist merely of the vascular core inside the cutinized epidermis. The well-developed stomata are numerous on the upper branches but rare below and confirm Lang's conclusion that this is a land plant. The course of the vascular strand in the H-shaped branches of the base of the plant is

Transactions of the Royal Society of Edinburgh.
Vol, 64, No. 17 (1960-61): Contributions to the Knowledge of Zosterophyllum myretonianum Penhallow from the Lower Old Red Sandstone of Angus. By K. M. Lele and J. Walton. Pp. 469-475+ 2 plates. 68 .

Vol. 64, No. 18 (1960-61): Tristichia ovensi gen. et sp. nov,, a Fast Lothian, By Albert $G$. Long. Pp. 477-489+4 plates. 8s. $6 d$.

(Edinburgh: Royal Society of Edinburgh, 1961.) now clear and this branching, though remaining characteristic, becomes understandable and Zosterophyllum takes its place as a normal rather than a problematical early plant.

A. G. Long's paper is the latest of a series dealing with petrifactions from the Lower Carboniferous of Berwickshire. Tristiehia is a new stem; it is slender (only 2-3 $\mathrm{mm}$ wide) and bears petioles as wide as itself, but much less vascular. The petioles (also known as compressions) fork repeatedly and their thread-like ends bear tiny terminal pinnules. Similar fertile petioles considered to be of the same plant bear terminal cupules from each of which numbers of seeds were macerated out, and the seeds are held to be the same as Stamnotesta previously described as petrifactions. Thus the microsporophyll alone remains unknown, but pollen grains are described from the tops of the seeds. Tristichia can now take its place along with Tetrastichia and other Lower Carboniferous Pteridosperms.

The Royal Society of Edinburgh is to be congratulated on maintaining the quality of its plates.

TOM M. HARRIS 